\title{
Synthesis of Pinpoint-Fluorinated Polycyclic Aromatic Hydrocarbons: Benzene Ring Extension Cycle Involving Microwave-Assisted $\mathrm{S}_{\mathrm{N}}$ Ar Reaction
}

\author{
Kohei Fuchibe, Hisanori Imaoka, and Junji Ichikawa*
}

\begin{abstract}
Fluoroarenes bearing no electron-withdrawing groups (non-activated fluoroarenes) readily underwent nucleophilic aromatic substitution with $\alpha$-cyanocarbanions under microwave irradiation. The sequence (i) formylalkylation involving the cyanoalkylation of fluoroarenes, (ii) difluorovinylidenation, and (iii) Friedel-Crafts-type cyclization, afforded one benzene ring-extended fluoroarenes in one cycle. Furthermore, the performance of multiple cycles successfully provided higher order pinpoint-fluorinated polycyclic aromatic hydrocarbons (F-PAHs)
\end{abstract}

Pinpoint-fluorinated PAHs (regioselectively fluorinated polycyclic aromatic hydrocarbons) are promising organic semiconducting materials ${ }^{1}$ because of the unique properties of the fluorine substituent. ${ }^{2}$ The high electronegativity of fluorine leads to the enhanced resistance of PAHs to aerial oxidation by lowering the energy level of their HOMO. In addition, the repulsive interaction between lone pairs in the fluorine $2 p$ orbitals and the adjacent $\pi$ electrons in the carbon $2 p$ orbitals perturbs the electron density of the extended $\pi$-systems, ${ }^{3}$ which would render these compounds highly soluble in polar organic solvents, leading to printable organic electronics. ${ }^{4}$ It is also worth mentioning the low steric impact of fluorine, whose introduction into $\mathrm{PAH}$ molecules should not change their molecular shape, would not affect much their $\pi-\pi$ stacking in the solid structure. ${ }^{5,6}$ Therefore, the effects of installing a single fluorine substituent in PAH skeletons would lead to advantageous semiconducting materials, such as THFsoluble fluorinated picenes, which exhibit p-type semiconducting behavior. ${ }^{5,7}$

To facilitate the efficient synthesis of pinpoint-fluorinated $\mathrm{PAHs}$, we have recently developed metal-catalyzed cyclizations of fluoroalkenes on the basis of the following benzene ring construction strategy (Scheme 1): (a) 1,1-difluoroallenes, readily prepared via difluorovinylidenation of aldehydes, ${ }^{8}$ undergo a Friedel-Crafts-type cyclization in the presence of a catalytic amount of indium(III) bromide. ${ }^{9}$ Subsequent DDQ (2,3-dichloro5,6-dicyano-p-benzoquinone) dehydrogenation affords pinpointfluorinated aromatic compounds (fluoroarenes). (b) These compounds were also accessible from 1,1-difluoroalkenes via a cationic palladium(II)-catalyzed cyclization ( Scheme 1). . $^{50,11}$

As the preparation of the substrates for the indium(III)catalyzed synthesis of pinpoint-fluorinated PAHs, i.e.,

[a] Dr. K. Fuchibe, H. Imaoka, and Prof. Dr. J. Ichikawa Division of Chemistry, Faculty of Pure and Applied Sciences, University of Tsukuba

Tsukuba, Ibaraki 305-8571 (Japan)

E-mail: junji@chem.tsukuba.ac.jp

Homepage: http://www.chem.tsukuba.ac.jp/junji/index.html

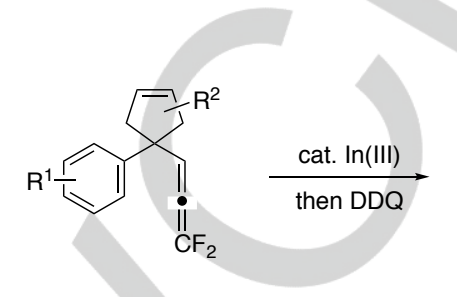<smiles></smiles>

(b)

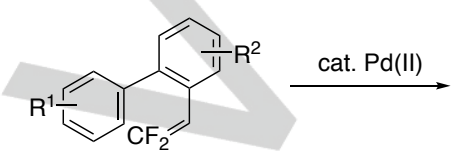<smiles>Fc1cc2[R]cccc2c2c1C=C[Se]C=2</smiles>

Scheme 1. F-PAH Syntheses.

difluoroallenes, involved fluoroarenes as starting materials, we envisioned a cyclic benzene ring extension strategy that would comprise the following steps (Scheme 2): (i) starting fluoroarenes would be subjected to formylalkylation via $S_{N} A r$ reaction to provide arylacetoaldehydes; (ii) the aldehydes would be then subjected to difluorovinylidenation; ${ }^{8}$ finally, (iii) the Friedel-Crafts-type cyclization of the obtained 1,1difluoroallenes ${ }^{9}$ would furnish the benzene ring-extended fluoroarenes.

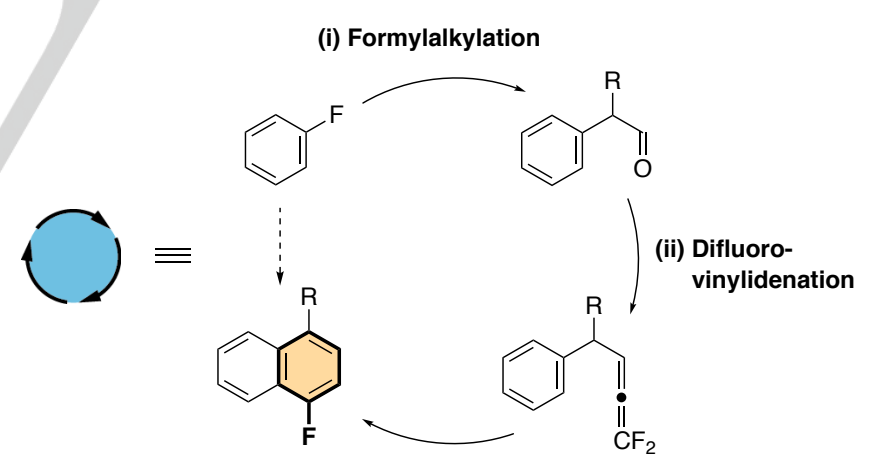

(iii) Friedel-Crafts-type Cyclization

Scheme 2. Benzene Ring Extension Cycle.

However, $S_{N} A r$ reactions of fluoroarenes have been conducted on those activated by electron-withdrawing groups, including halogenes and trifluoromethyl groups, ${ }^{12}$ and the $S_{N} A r$ reaction of non-activated fluoroarenes have been limited to those on benzene $\pi$ systems. ${ }^{13}$ In the course of this study, we found that microwave irradiation ${ }^{14}$ significantly facilitated the desired $S_{N} A r$ reaction of non-activated fluoroarenes with naphthalene or higher order PAH $\pi$ systems (Table 1$).{ }^{15}$ When fluoronaphthalene $1 \mathrm{a}$ and propionitrile (4.0 equiv) were heated in refluxing THF using a conventional oil bath in the presence of 
potassium bis(trimethylsilyl)amide (KHMDS, 4.0 equiv, entry 1), the desired alkylated naphthalene $\mathbf{2 a}$ was obtained albeit in low yields, i.e., 6-17\% (Table 1, entries 1 and 2). In contrast, microwave irradiation at $80{ }^{\circ} \mathrm{C}$ dramatically increased the yield of $2 \mathbf{a}$ to $70 \%$ (entry 3 ). Further optimization afforded yields up to $82 \%$ after isolation (entries 4 and 5). ${ }^{16,17}$

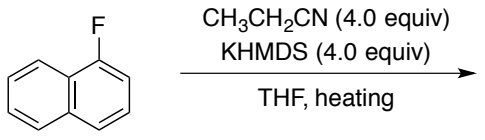

1a

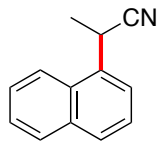

$2 a$
Table 1. Optimization for $\mathrm{S}_{N} A r$ Reaction. ${ }^{[\mathrm{a}]}$

\begin{tabular}{lllll}
\hline Entry & Heating & $\begin{array}{l}\text { Concentration of } \\
\text { 1a [M] }\end{array}$ & Conditions & $\begin{array}{l}\text { Yield of } \\
\text { 2a [\%] }\end{array}$ \\
\hline 1 & Oil Bath & 0.25 & $65{ }^{\circ} \mathrm{C}, 24 \mathrm{~h}$ & 6 \\
2 & Oil Bath & 0.25 & $80{ }^{\circ} \mathrm{C},{ }^{[\mathrm{b}]} 16 \mathrm{~h}$ & 17 \\
3 & Microwave & 0.25 & $80^{\circ} \mathrm{C},{ }^{[\mathrm{b}]} 1 \mathrm{~h}$ & 70 \\
4 & Microwave & 0.25 & $80^{\circ} \mathrm{C},{ }^{[\mathrm{b}]} 1.5 \mathrm{~h}$ & 77 \\
5 & Microwave & 0.50 & $80^{\circ} \mathrm{C},{ }^{[\mathrm{b}]} 1.5 \mathrm{~h}$ & $88(82)$ \\
\hline
\end{tabular}

[a] ${ }^{1} \mathrm{H}$ NMR yield based on an internal standard $\mathrm{CH}_{2} \mathrm{Br}_{2}$. Isolated yield in parentheses. [b] The reaction was conducted in a sealed vessel.

Acetonitrile (Table 2, entry 1) reacted with 1a in a manner similar to that of propionitrile, affording the corresponding primary nitrile $\mathbf{2 b}$ in $53 \%$ yield under microwave irradiation. In contrast, 2b was not obtained when performing the $S_{N} A r$ reaction of acetonitrile under oil bath heating (THF, reflux, $18 \mathrm{~h}$ ). Decanonitrile, whose C8 alkyl chain is expected to enhance the solubility of PAHs, also afforded the corresponding naphthalene 2 c in $90 \%$ yield (entry 2 ). Thus, as well as<smiles>Fc1cccnc1</smiles><smiles>Fc1cc2ccccc2c2ccccc12</smiles>

1c<smiles>Fc1cc2ccccc2c2ccc3ccccc3c12</smiles>

$1 e$<smiles>Fc1cc(-c2ccccc2)c2ccccc2c1</smiles>

$1 d$

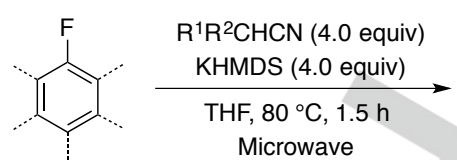

1 Microwave

Table 2. Microwave-assisted $S_{N} A r$ Reaction ${ }^{[a]}$

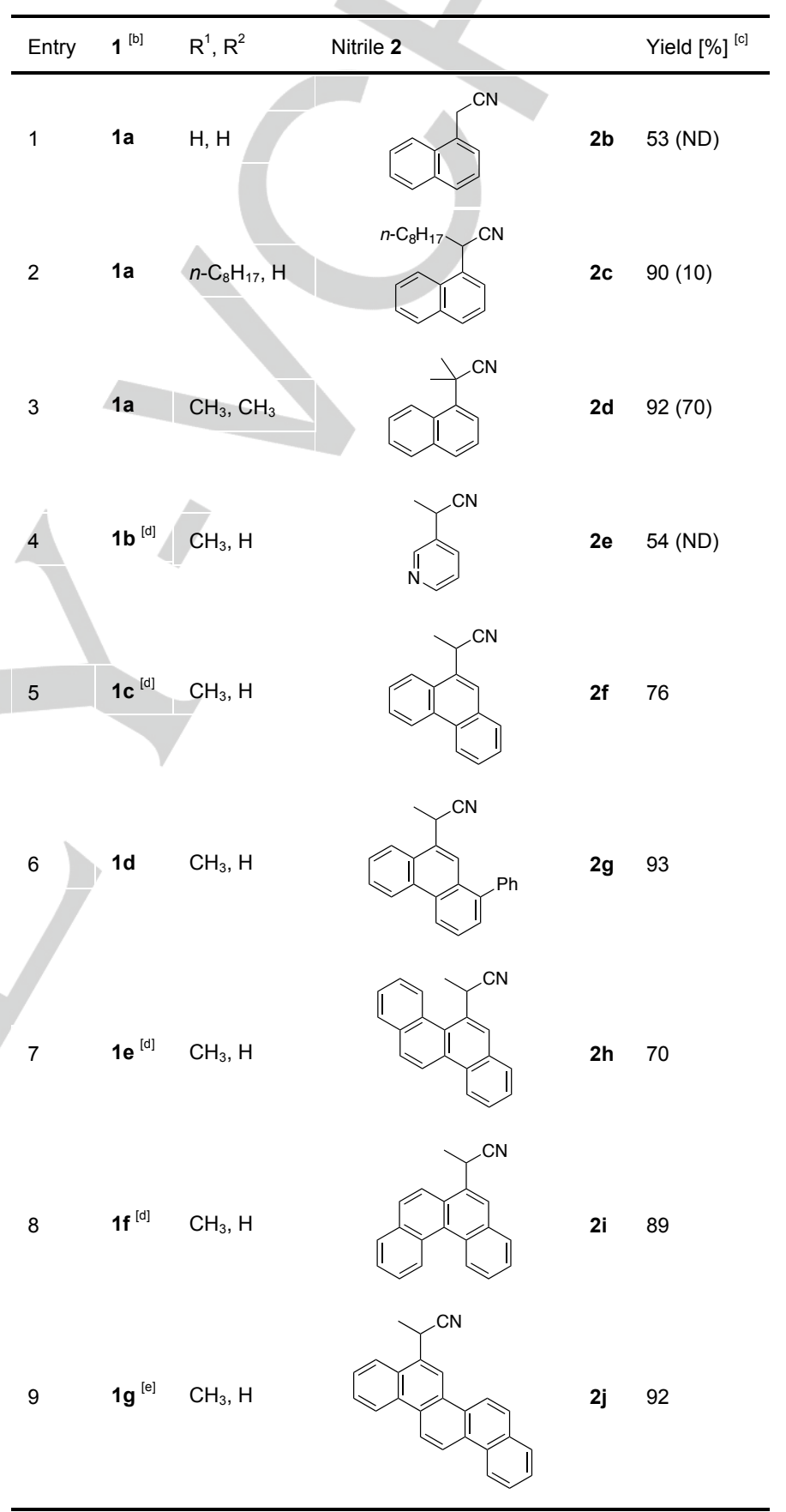

[a] The reaction was conducted in a sealed vessel. [b] Unless otherwise noted, concentration of 1 was $0.50 \mathrm{M}$. [c] Isolated yield. The yield obtained under oil bath heating (THF, $65^{\circ} \mathrm{C}$ ) is shown in parentheses. [d] $10.25 \mathrm{M}$. [e] $1 \mathrm{~g} 0.008$ M. ND = Not detected by ${ }^{1} \mathrm{H}$ NMR spectroscopy. 
secondary nitriles, ${ }^{13 a}$ acetonitrile and primary nitriles were demonstrated to react with fluoronaphthalene under microwave irradiation. Isobutyronitrile, which is an effective substrate for the nucleophilic aromatic substitution, gave $\mathbf{2 d}$ in $92 \%$ yield (entry 3 )

The microwave-assisted $S_{N} A r$ reaction was applicable to a wide variety of fluoroarenes (Figure 1). Thus, 3-fluoropyridine (1b) afforded the corresponding product $2 \mathrm{e}$ in $54 \%$ yield (Table 2 , entry 4). Substitution of fluorophenanthrenes $1 \mathrm{c}$ and $\mathbf{1 d}$ also worked well to afford the corresponding $\mathbf{2 f}$ and $\mathbf{2 g}$ in $76 \%$ and $93 \%$ yields, respectively (entries 5 and 6 ). Fluorochrysene ([4]phenacene) $1 \mathrm{e}$ and fluoro[4]helicene 1f were successfully transformed into $\mathbf{2} \mathbf{h}$ and $\mathbf{2} \mathbf{i}$ in $70 \%$ and $89 \%$ yields, respectively (entries 7 and 8), proving that the substitution proceeded smoothly even at the bay region of the phenanthrene substructure of $\mathbf{1 e}$. Finally, fluoropicene ([5]phenacene) $\mathbf{1 g}$ underwent the substitution under identical conditions to give $2 \mathrm{j}$ in $92 \%$ yield (entry 9 ). Thus, the scope of microwave-assisted $S_{N} A r$ reaction was expanded to include non-activated fluoroarenes with extended $\pi$ systems.

With the microwave-assisted alkylation method in hand, we sought to explore its application to the planned benzene ring extension (Scheme 3). Nitrile $\mathbf{2 a}$, obtained as detailed above from 1a (Table 1, entry 5: step 1, $82 \%$ yield), was subjected to half reduction with diisobutylaluminium hydride (DIBAL) to afford aldehyde $\mathbf{3 a}$ in $81 \%$ yield (step 2). Difluorovinylidenation of $\mathbf{3 a}$ afforded 1,1 -difluoroallene $\mathbf{4 a}$ in $73 \%$ yield in two steps (steps 3 and 4). Then 4a underwent Friedel-Crafts-type cyclization under indium(III) catalysis to provide benzene ring-extended fluorophenanthrene $1 \mathrm{~h}$ in $94 \%$ yield (step 5), thus completing the first cycle. In a similar manner, the benzene ring extension starting from $\mathbf{2 c}$ afforded the corresponding $\mathbf{1} \mathbf{i}$ in good yield.<smiles>Fc1cccc2ccccc12</smiles>

1) Table 1, Entry $5,82 \%(2 a)$

2) $\mathrm{HAli}-\mathrm{Bu}_{2}(1.2$ equiv) toluene, $-78^{\circ} \mathrm{C}, 2 \mathrm{~h}$

1a or Table 2, Entry 2, $90 \%(2 \mathrm{c})$

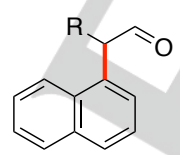

$81 \%, \mathbf{3 a}\left(\mathrm{R}=\mathrm{CH}_{3}\right)$ $73 \%, \mathbf{3 b}\left(\mathrm{R}=n-\mathrm{C}_{8} \mathrm{H}_{17}\right)$

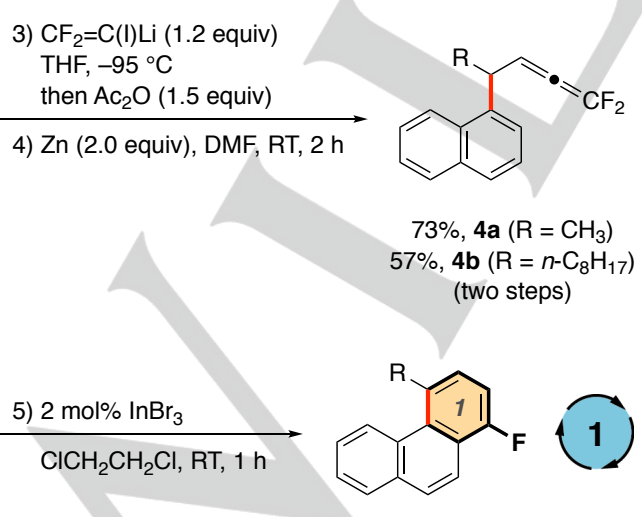

$94 \%, \mathbf{h}\left(\mathrm{R}=\mathrm{CH}_{3}\right)$ Quant, 1i $\left(\mathrm{R}=n-\mathrm{C}_{8} \mathrm{H}_{17}\right)$
Scheme 3. Benzene Ring Extension of 1-Fluoronaphthalene (1st Cycle).
By repeating the same protocol with fluoroarene $1 \mathrm{~h}$, higher order pinpoint-fluorinated PAHs were synthesized (Table 3). Thus, $1 \mathrm{~h}$ was subjected to the second ring extension to afford pinpoint-fluorinated chrysene $\mathbf{1 j}$ (entry 1). The third ring extension of $\mathbf{1} \mathbf{j}$ was performed to afford pinpoint-fluorinated picene $\mathbf{1 k}$ (entry 2).

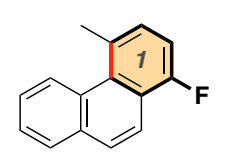

$1 \mathrm{~h}$

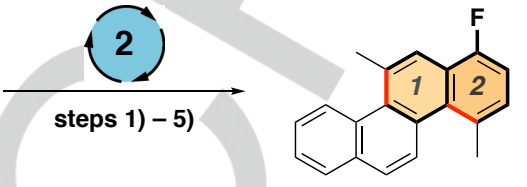

1j

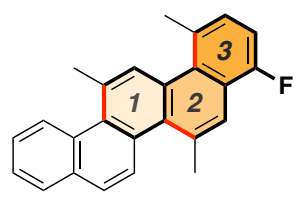

Table 3. Benzene Ring Extension of Fluoroarenes (2nd and 3rd Cycles) ${ }^{[a] b]}$

\begin{tabular}{|c|c|c|c|c|c|c|}
\hline \multirow{2}{*}{ Entry } & \multirow{2}{*}{ Cycle } & \multirow{2}{*}{$\begin{array}{l}\text { Starting } \\
\text { Compd }\end{array}$} & \multicolumn{4}{|c|}{ Yield [\%] } \\
\hline & & & Step 1) & Step 2) & Steps 3,4$)^{[c]}$ & Step 5) \\
\hline 1 & 2nd & $1 \mathrm{~h}$ & $71^{[\mathrm{d}]}$ & 85 & 64 & $87, \mathbf{1 j}$ \\
\hline 2 & $3 r d$ & $1 j$ & $64^{[\mathrm{e}]}$ & 79 & 36 & $79, \mathbf{1 k}$ \\
\hline
\end{tabular}

[a] Isolated. [b] For steps 1) to 5), see Scheme 3. [c] Two-step yield. [d] 1 h 0.5 M. [e] 1j $0.25 \mathrm{M}$.

The benzene ring extension was successfully applied to not only terminal fluoroarenes but also internal ones (Scheme 4). Pinpoint-fluorinated triphenylene $\mathbf{1 l}$ (top) was successfully synthesized from fluorophenanthrene $1 \mathrm{c}$ via nitrile $\mathbf{2 f}$, whereas pinpoint-fluorinated triphenylene $1 \mathrm{~m}$ (bottom) was similarly obtained from fluorohelicene $\mathbf{1} \mathbf{f}$ via $\mathbf{2} \mathbf{i}^{18}$

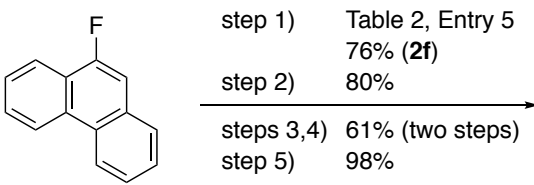

1c

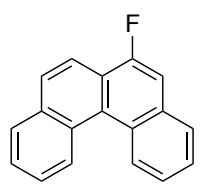

$1 f$

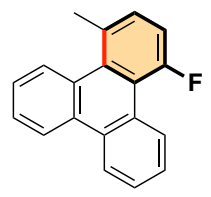

11

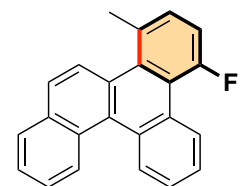

$1 \mathrm{~m}$
Scheme 4. Benzene Ring Extension of Internal Fluoroarenes. 
It is worth noting that the benzene ring extension using primary nitriles facilitated the synthesis of PAHs bearing a substituent in the bay region (Schemes 3, 4 and Table 3). Although effects of bay substitution are of importance not only from the viewpoint of organic devices but also from the viewpoint of cancer research, ${ }^{[19]}$ synthetic methods applicable to the molecules have been rare. ${ }^{[20]}$ The benzene ring extension thus contributes to a wide range of research areas through providing the bay-substituted PAHs.

In summary, we have achieved a microwave-assisted $S_{N} A r$ reaction of non-activated fluoroarenes with extended $\pi$ systems. This $S_{N} A r$ reaction along with difluorovinylidenation and cationic cyclization facilitated a novel benzene ring extension cycle, by which terminal and internal fluoroarenes were converted to the corresponding one benzene ring-extended fluoroarenes in good yields. Thus, the cycle increases the variety of pinpointfluorinated PAHs.

\section{Experimental Section}

Microwave-assisted $S_{N} A r$ reaction of non-activated fluoroarenes (step 1): synthesis of nitrile $\mathbf{2 a}$ is described as a typical procedure. To a THF solution $(2.4 \mathrm{~mL})$ of KHMDS $(1.03 \mathrm{~g}, 4.80 \mathrm{mmol})$ was added 1 fluoronaphthalene $(1 \mathrm{a}, 155 \mu \mathrm{L}, 1.20 \mathrm{mmol})$ at room temperature. After propionitrile $(340 \mu \mathrm{L}, 4.75 \mathrm{mmol})$ was added, microwave $(65 \mathrm{~W})$ was irradiated at $80^{\circ} \mathrm{C}$ for $90 \mathrm{~min}$. The reaction mixture was poured into aqueous hydrochloric acid $(2 \mathrm{M}, 5 \mathrm{~mL})$ at room temperature. Organic materials were extracted with ethyl acetate three times. The combined extracts were washed with brine and dried over anhydrous sodium sulfate.

To the residue $(396 \mathrm{mg})$ were added dibromomethane $(109 \mathrm{mg})$ and $\alpha, \alpha, \alpha$-trifluorotoluene $(24 \mathrm{mg})$ as internal standards. Analysis by NMR spectroscopy indicated that nitrile $2 \mathrm{a}$ was generated in $88 \%$ yield (by ${ }^{1} \mathrm{H}$ NMR based on $\mathrm{CH}_{2} \mathrm{Br}_{2}$ ) and fluoronaphthalene 1a was consumed completely (by ${ }^{19} \mathrm{~F}$ NMR based on $\mathrm{CF}_{3} \mathrm{Ph}$ ). The residue was purified by column chromatography on silica gel (hexane/ethyl acetate, 10:1) to give nitrile $2 \mathrm{a}$ ( $178 \mathrm{mg}, 82 \%$ yield) as a colorless liquid.

Half-reduction of nitriles (step 2): preparation of aldehyde 3a is described as a typical procedure. To a toluene solution $(150 \mathrm{~mL})$ of nitrile 2a $(28.2 \mathrm{~g}, 156 \mathrm{mmol})$ was added a toluene solution of diisobutylaluminium hydride (DIBAL, $1.00 \mathrm{M}, 184 \mathrm{~mL}, 181 \mathrm{mmol}$ ) at $-78{ }^{\circ} \mathrm{C}$. After being stirred for $3 \mathrm{~h}$ at the temperature, aqueous hydrochloric acid $(6 \mathrm{M}, 300 \mathrm{~mL})$ was added and the mixture was allowed to warm to $0{ }^{\circ} \mathrm{C}$. The mixture was filtered through a pad of celite using ethyl acetate as an eluent. Organic materials were extracted with ethyl acetate three times. The combined extracts were washed with brine and dried over anhydrous sodium sulfate. After removal of the solvent under reduced pressure, the residue was purified by column chromatography on silica gel (hexane/ethyl acetate, $4: 1)$ to give aldehyde $\mathbf{3 a}(19.9 \mathrm{~g}, 81 \%$ yield) as a yellow liquid.

Difluorovinylidenation of aldehydes (steps 3 and 4): preparation of 1,1-difluoroallene $4 \mathbf{a}$ is described as a typical procedure. To a THF solution $(350 \mathrm{~mL}$ ) of lithium diisopropylamide (LDA, $479 \mathrm{mmol})$, prepared from diisopropylamine $(48.3 \mathrm{~mL}, 479 \mathrm{mmol})$ and butyllithium $(1.60 \mathrm{M}$ in hexane, $300 \mathrm{~mL}, 480 \mathrm{mmol}$ ) at $-78{ }^{\circ} \mathrm{C}$ for $30 \mathrm{~min}$, was added $1,1,1$ trifluoro-2-iodoethane $(23.4 \mathrm{~mL}, 240 \mathrm{mmol})$ at $-95^{\circ} \mathrm{C}$. After being stirred for $30 \mathrm{~min}$ at the temperature, a THF solution $(300 \mathrm{~mL})$ of aldehyde $3 \mathbf{a}$ (368 $\mathrm{mg}, 200 \mathrm{mmol}$ ) was added. The mixture was stirred at $-90^{\circ} \mathrm{C}$ for 1 $\mathrm{h}$ and allowed to warm to $-50^{\circ} \mathrm{C}$. Acetic anhydride $(28.3 \mathrm{~mL}, 299 \mathrm{mmol})$ was added. After the mixture was allowed to warm to $0{ }^{\circ} \mathrm{C}$ and stirred for $5 \mathrm{~h}$, the reaction was quenched with saturated aqueous ammonium chloride $(150 \mathrm{~mL})$. Organic materials were extracted with ethyl acetate three times. The combined extracts were washed with brine and dried over anhydrous sodium sulfate. After removal of the solvent under reduced pressure, a crude 3,3-difluoro-2-iodoallyl acetate was obtained. This material was used without further purification for the next step.

To a DMF suspension $(120 \mathrm{~mL})$ of zinc powder $(2.61 \mathrm{~g}, 399 \mathrm{mmol})$ was added a DMF solution $(180 \mathrm{~mL})$ of the crude acetate at $-20^{\circ} \mathrm{C}$. After being stirred for $2 \mathrm{~h}$ at the temperature, the mixture was allowed to warm to room temperature. The mixture was filtered through a pad of celite using ether as an eluent, and saturated aqueous ammonium chloride $(100 \mathrm{~mL})$ was added. Organic materials were extracted with ether three times. The combined extracts were washed with brine and dried over anhydrous sodium sulfate. After removal of the solvent under reduced pressure, the residue was purified by column chromatography on silica gel (hexane) to give 1,1-difluoroallene $\mathbf{4 a}$ ( $33.6 \mathrm{~g}, 73 \%$ yield, 2 steps) as a colorless liquid.

In(III)-catalyzed cyclization of difluoroallenes (step 5): synthesis of fluoroarene $1 \mathrm{~h}$ is described as a typical procedure. To a 1,2dichloroethane suspension $(4 \mathrm{~mL})$ of indium(III) bromide $(4 \mathrm{mg}, 0.01$ $\mathrm{mmol}$ ) was added a 1,2-dichloroethane solution (10 mL) of 1,1difluoroallene $4 \mathrm{a}(120 \mathrm{mg}, 0.523 \mathrm{mmol})$ at room temperature. After being stirred for $1 \mathrm{~h}$, the mixture was then poured into $\mathrm{pH} 7$ phosphate buffer $(7$ $\mathrm{mL}$ ). Organic materials were extracted with dichloromethane three times. The combined extracts were washed with brine and dried over anhydrous sodium sulfate. After removal of the solvent under reduced pressure, the residue was purified by column chromatography on silica gel (hexane) to give fluoroarene $1 \mathrm{~h}$ (103 $\mathrm{mg}, 94 \%$ yield) as colorless crystals.

\section{Acknowledgements}

This research was supported by JSPS KAKENHI Grant Number JP16H04105 (J.I.), MEXT KAKENHI Grant Number JP16H01002 (J.I.), and JSPS KAKENHI Grant Number JP15K05414 (K.F.). Tosoh F-Tech, Inc. is acknowledged for the generous gift of 1,1,1-trifluoro-2-iodoethane.

Keywords: aromatic substitution $\bullet$ fluorine $\bullet$ indium $\bullet$ microwave chemistry $\cdot$ ring extension

[1] For fluorine-free PAHs as organic semiconducting materials, including phenacenes, see: a) H. Okamoto, N. Kawasaki, Y. Kaji, Y. Kubozono, A. Fujiwara, M. Yamaji, J. Am. Chem. Soc. 2008, 130, 10470-10471; b) J. E. Anthony, Angew. Chem. Int. Ed. 2008, 47, 452-483; c) Y. Yamashita, Sci. Technol. Adv. Mater. 2009, 10, 024313; d) Y. Kubozono, X. He, S. Hamao, K. Teranishi, H. Goto, R. Eguchi, T. Kambe, S. Gohda, Y. Nishihara, Eur. J. Inorg. Chem. 2014, 2014, 3806-3819.

[2] a) B. E. Smart, in Organofluorine Chemistry, Principles and Commercial Applications (Eds.: R. E. Banks, B. E. Smart, J. C. Tatlow), Plenum Press, New York, 1994, pp. 57-88; b) T. Hiyama, in Organofluorine Compounds: Chemistry and Applications, Springer, Berlin, 2000, pp. 123; c) K. Uneyama, in Organofluorine Chemistry, Blackwell, Oxford, 2006, pp. 1-100.

[3] S. D. Sharma, S. Doraiswamy, Indian J. Pure Appl. Phys. 1983, 21, 445-452.

[4] a) Printed Organic and Molecular Electronics (Eds.: D. Gamota, P. Brazis, K. Kalyanasundaram, J. Zhang), Springer, Berlin, 2005; b) M. Singh, H. M. Haverinen, P. Dhagat, G. E. Jabbour, Adv. Mater. 2010, 22, 673-685.

[5] a) K. Fuchibe, T. Morikawa, K. Shigeno, T. Fujita, J. Ichikawa, Org. Lett. 2015, 17, 1126-1129; b) K. Fuchibe, T. Morikawa, R. Ueda, T. Okauchi, J. Ichikawa, J. Fluorine Chem. 2015, 179, 106-115. 
[6] F. B. Mallory, C. W. Mallory, C. K. Regan, R. J. Aspden, A. B. Ricks, J. M. Racowski, A. I. Nash, A. V. Gibbons, P. J. Carroll, J. M. Bohen, J. Org. Chem. 2013, 78, 2040-2045.

[7] Polyfluorinated PAHs, typically bearing tetrafluorobenzo moieties, have been prepared for developing organic $n$-type semiconducting materials during this decade. See: a) F. Babudri, G. M. Farinola, F. Naso, R. Ragni, Chem. Commun. 2007, 1003-1022; b) M. L. Tang, Z. Bao, Chem. Mater. 2011, 23, 446-455.

[8] a) M. Yokota, K. Fuchibe, M. Ueda, Y. Mayumi, J. Ichikawa, Org. Lett. 2009, 11, 3994-3997; b) K. Oh, K. Fuchibe, J. Ichikawa, Synthesis 2011, 881-886; c) K. Oh, K. Fuchibe, M. Yokota, J. Ichikawa, Synthesis 2012, 44, 857-861; d) K. Fuchibe, M. Abe, K. Oh, J. Ichikawa, Org. Synth. 2016, 93, 352-366.

[9] a) K. Fuchibe, Y. Mayumi, N. Zhao, S. Watanabe, M. Yokota, J. Ichikawa, Angew. Chem. Int. Ed. 2013, 52, 7825-7828; b) K. Fuchibe, Y. Mayumi, M. Yokota, H. Aihara, J. Ichikawa, Bull. Chem. Soc. Jpn. 2014, 87, 942-949.

[10] Syntheses of pinpoint-fluorinated PAHs via ring construction other than ours (refs 5 and 9) have been mainly performed by oxidative photocyclization. See: a) S. Mirsadeghi, G. K. B. Prasad, N. Whittaker, D. R. Thakker, J. Org. Chem. 1989, 54, 3091-3096; b) H. Li, K.-H. He, J. Liu, B.-Q. Wang, K.-Q. Zhao, P. Hu, Z.-J. Shi, Chem. Commun. 2012 , 48, 7028-7030; c) Z. Li, R. J. Twieg, Chem. Eur. J. 2015, 21, 15534 15539; d) S. Banerjee, S. Sinha, P. Pradhan, A. Caruso, D. Liebowitz, D. Parrish, M. Rossi, B. Zajc, J. Org. Chem. 2016, 81, 3983-3993. See also: e) K. Kamikawa, I. Takemoto, S. Takemoto, H. Matsuzaka, J. Org. Chem. 2007, 72, 7406-7408; f) H. Tsuji, Y. Ueda, L. Ilies, E. Nakamura, J. Am Chem. Soc. 2010, 132, 11854-11855.

[11] For reviews on synthesis of fluorinated arenes via fluorine introduction, see: a) M. G. Campbell, T. Ritter, Chem. Rev. 2015, 115, 612-633; b) P. A. Champagne, J. Desroches, J.-D. Hamel, M. Vandamme, J.-F. Paquin, Chem. Rev. 2015, 115, 9073-9174.

[12] For reviews on $S_{N} A r$ reactions, see: a) $H$. Amii, K. Uneyama, Chem. Rev. 2009, 109, 2119-2183; b) C. Liu, B. Zhang, Chem. Rec. 2016, 16, $667-687$.

[13] [Carbon nucleophiles] a) S. Caron, E. Vazquez, J. M. Wojcik, J. Am. Chem. Soc. 2000, 122, 712-713; b) X. Ji, T. Huang, W. Wu, F. Liang, S.
Cao, Org. Lett. 2015, 17, 5096-5099. [Phosphine nucleophiles] c) M. Tepper, O. Stelzer, T. Häusler, W. S. Sheldrick, Tetrahedron Lett. 1997, 38, 2257-2258; d) M. W. Haenel, S. Oevers, J. Bruckmann, J. Kuhnigk C. Krüger, Synlett 1998, 301-303. [Nitrogen nucleophiles] e) F. Diness, D. P. Fairlie, Angew. Chem. Int. Ed. 2012, 51, 8012-8016.

[14] For reviews on microwave-assisted organic synthesis, see: a) C. O. Kappe, Angew. Chem. Int. Ed. 2004, 43, 6250-6284; b) S. Caddick, R. Fitzmaurice, Tetrahedron 2009, 65, 3325-3355.

[15] For specific examples of the effect of microwave irradiation on $S_{N} A r$ reaction, see: a) S.-W. Yang, G. Ho, D. Tulshian, W. J. Greenlee, J. Anthes, X. Fernandez, R. L. McLeod, J. A. Hey, X. Xu, J. Med. Chem. 2009, 52, 5323-5329. See also: b) R. Y. lliashenko, N. Y. Gorobets, A. O. Doroshenko, Tetrahedron Lett. 2011, 52, 5086-5089; c) R. Singh, B. K. Allam, D. S. Raghuvanshi, K. N. Singh, Tetrahedron 2013, 69, 10381042.

[16] See Supporting Information for details.

[17] The substitution of 1a with ethyl propionate did not proceed under the identical conditions to Table 1, Entry 5. The substitution of 1-bromo- or 1-chloronaphthalene with propionitrile hardly proceeded to afford $\mathbf{2 a}$ in $3 \%$ yield each.

[18] For reviews on triphenylene syntheses, see: a) D. Pérez, E. Guitián, Chem. Soc. Rev. 2004, 33, 274-283; b) D. Pérez, D. Peña, E. Guitián, Eur. J. Org. Chem. 2013, 2013, 5981-6013.

[19] a) R. E. Lehr, S. Kumar, W. Levin, A. W. Wood, R. L. Chang, A. H. Conney, H. Yagi, J. M. Sayer, D. M. Jerina, in Polycyclic Hydrocarbons and Carcinogenesis (Ed.: R. D. Harvey), American Chemical Society, 1985, Vol. 283, pp. 63-84; b) S. S. Hecht, S. Amin, A. A. Melikian, E. J. Lavoie, D. Hoffmann, in Polycyclic Hydrocarbons and Carcinogenesis (Ed.: R. D. Harvey), American Chemical Society, 1985, Vol. 283, pp. 85-105.

[20] a) R. J. Olsen, S. R. Pruett, J. Org. Chem. 1985, 50, 5457-5460; b) J. Carreras, G. Gopakumar, L. Gu, A. Gimeno, P. Linowski, J. Petuškova, W. Thiel, M. Alcarazo, J. Am. Chem. Soc. 2013, 135, 18815-18823. See also: c) T. Fujita, I. Takahashi, M. Hayashi, J. Wang, K. Fuchibe, J. Ichikawa, Eur. J. Org. Chem. 2017, 262-265. 


\section{Entry for the Table of Contents}

\section{COMMUNICATION}<smiles>Fc1ccc(I)cc1I</smiles>

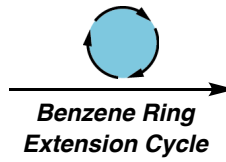<smiles>Cc1c(C)c(C)c2c(F)cccc2c1F</smiles><smiles>c1ccccc1</smiles>

Formylalkylation

(Microwave-assisted $\mathrm{S}_{\mathrm{N}} \mathrm{Ar}$ )

(ii) Difluorovinylidenation

(iii) Friedel-Crafts-type cyclization

Fluoroarenes bearing no electron-withdrawing groups (non-activated fluoroarenes) readily underwent nucleophilic aromatic substitution with $\alpha$-cyanocarbanions under microwave irradiation. The sequence (i) formylalkylation involving the cyanoalkylation of fluoroarenes, (ii) difluorovinylidenation, and (iii) Friedel-Craftstype cyclization, afforded one benzene ring-extended fluoroarenes in one cycle. Furthermore, the performance of multiple cycles successfully provided higher order pinpoint-fluorinated polycyclic aromatic hydrocarbons (F-PAHs).
Kohei Fuchibe, Hisanori Imaoka, and Junji Ichikawa*

Page No. - Page No.

Synthesis of Pinpoint-Fluorinated Polycyclic Aromatic Hydrocarbons: Benzene Ring Extension Cycle Involving Microwave-Assisted $\mathrm{S}_{\mathrm{N}} \mathrm{Ar}$ Reaction 